\title{
ENVIRONMENTAL IMPACTS COMPARISON BETWEEN ON-SITE VS. PREFABRICATED JUST-IN-TIME (PREFAB-JIT) REBAR SUPPLY IN CONSTRUCTION PROJECTS
}

\author{
Yong-Woo KIM ${ }^{\mathrm{a}}$, Rahman AZARI-N ${ }^{\mathrm{a}}$, June-Seong YI ${ }^{\mathrm{b}}$, Jinwoo BAE \\ ${ }^{a}$ College of Built Environments, University of Washington, Seattle, WA, USA \\ ${ }^{b}$ Department of Architectural Engineering, Ewha Womans University, Seoul, South Korea
}

Received 21 Sep. 2011; accepted 14 Dec. 2011

\begin{abstract}
In the on-site rebar delivery system, as the common method of rebar supply in the construction industry, reinforced steel bars are delivered in large batches from supplier's facilities through contractor's warehouse to the construction site. Rebars are then fabricated on-site and installed after assembly. In the new delivery system, called prefabrication Just-In-Time (prefab-JIT) system, the off-site cut and bend along with frequent rebar delivery to the site are applied in order to improve the process and increase its efficiency. The main objective of this paper is to assess and compare the environmental impacts resulting from the air emissions associated with the two rebar delivery systems in a case study construction project. Environmental impact categories of interest include global warming, acidification, eutrophication, and smog formation. A process-based cradle-to-gate life cycle assessment methodology is applied to perform the analysis. The results show that the prefab-JIT rebar delivery system causes less contribution to all mentioned environmental impact categories compared with a traditional on-site delivery system.
\end{abstract}

Keywords: on-site rebar delivery system; prefab-JIT; life cycle; environmental impacts.

Reference to this paper should be made as follows: Kim, Y.-W.; Azari-N., R.; Yi, J.-S.; Bae, J. 2013. Environmental impacts comparison between on-site vs. prefabricated Just-In-Time (prefab-JIT) rebar supply in construction projects, Journal of Civil Engineering and Management 19(5): 647-655. http://dx.doi.org/10.3846/13923730.2013.795186.

\section{Introduction}

Construction industry is one of the largest industries and at the same time among the industries which cause highest levels of pollution (Horvath 2004). Over the recent decades, the natural environment has gained increasing importance to construction firms and many contractors have started to realize their impacts on the environment and take actions to reduce them.

The growing body of literature addressing the environmental impacts of construction industry demonstrates the importance of the issue. A survey of existing knowledge in the field shows various attempts to assess the environmental life cycle impacts associated with construction materials and buildings (Koch 1992; Buchanan, Honey 1994; Meil 1994; Junnila, Horvath 2003; Petersen, Solberg 2005; Gustavsson et al. 2006; Gillespie et al. 2007; Werner, Richter 2007; Bribián et al. 2011). The focus in most of the literature is on the life cycle impacts of specific building materials. These studies, however, either fail to include the environmental impacts of the material delivery systems or simply use rough approximations which, in most cases, do not match the reality. The main reason for this has to do with the complexity of delivery systems as well as the limitations associated with applied methodologies.

Reinforced steel bars are important components in the construction of contemporary commercial buildings, and their type of delivery is considered a critical factor in meeting the budget and schedule targets (Polat, Ballard 2003). Traditionally, the construction industry has used a delivery system in which rebars are delivered from the supplier's facility or the contractor's warehouse to the construction site in large batches. Rebars are then fabricated (i.e. cut and bent) on-site and positioned for assembly. Due to the large on-site yard areas and the holding costs needed in this system, a new rebar delivery system inspired by lean principles has started to gain attention in the industry. The new system which can be called prefabJIT [prefabrication with Just-In-Time (JIT) delivery] applies off-site cut and bend (i.e. prefabrication) of rebars along with frequent delivery of them in small

Corresponding author: June-Seong Yi

E-mail: jsyi@ewha.ac.kr 
batches as needed over the construction process. Although the new system requires more frequent delivery of rebar batches, it omits the on-site yard space requirements as well as the delivery within the construction site (i.e. on-site yard to building).

Arbulu and Ballard (2004) showed that this lean delivery system improves productivity due to prefabrication. While this study and most of other relevant research regarding delivery systems focus on how to reduce the lead time using process improvements (Arbulu et al. 2003; Akel et al. 2004; Kim et al. 2007), they often ignore the environmental life cycle impacts of the systems.

This paper intends to assess and compare the environmental impacts of two rebar delivery systems, including the traditional system (on-site fabrication along with large batch delivery) and the prefab-JIT system, in a case study construction project using a process-based cradle-to-gate life cycle assessment (LCA) methodology. To do this, the goal and scope of the project are first defined. Then, an inventory modeling is performed by identifying the unit processes of the two systems and tracking and quantifying the environmental (material, primary energy, air emissions, etc.) and economic flows (transportation, electricity, etc.) associated with the unit processes. At the next phase, contributions of the two systems to the environmental impact categories are assessed. Impact categories of interest include acidification, eutrophication, global warming, and smog formation. Finally, the authors interpret the LCA results and identify the critical factors affecting the environmental impacts of the two systems.

The case study used for the study of the prefabJIT delivery system is a high-rise condominium construction project located in downtown Seattle, USA, where the system has actually been applied. The rebar delivery occurs from a rebar prefabrication plant in Tacoma, USA, to the location of the case study project in Seattle, USA.

The model for traditional rebar delivery system in this study was hypothetically modified from the prefab-JIT delivery system used in the case study. For the traditional rebar delivery system, the rebar products were assumed to be delivered on the construction site in large batch sizes and to be fabricated on-site.

The application of the traditional system and the prefab-JIT delivery system in the case study implies differences in equipment use, transportation distances, rebar loss rate, etc. between the two which will be explained later in this paper.

\section{LCA methodology}

LCA is a quantitative approach for assessing what energy sources and materials and in what quantities are used and/or wasted throughout the life cycle of a product or system. A full life cycle spans the raw material extraction, material processing, product manufacturing, operation and maintenance, and finally disposal and material recovery activities. The quantities of needed transportation between these processes as well as the required fuels are also considered in life cycle assessments.

To assess the environmental life cycle impacts of the two rebar delivery systems, we implemented the process-based cradle-to-gate LCA methodology according to ISO 14040:2006 and ISO 14044:2006 standards. The methodology addresses four major phases in its assessment including the goal and scope definition, inventory modeling and analysis, impact assessment and interpretation of the results. The outcome would be an LCA study which is ISO 14040 series compliant.

The inventory model for each delivery system was developed using a variety of data sources to ensure the quality of data and to fill the data gaps. In each model, the life cycle energy use (fossil, petroleum, coal, natural gas, diesel, electricity, and propane) and air emissions contributing to global warming, photochemical smog, acidification, and eutrophication were tracked and quantified. Then, contributions to the impact categories were assessed and the results of the two models were compared and interpreted.

\section{Goal and scope definition}

The goal and scope definition, as the first phase of LCA methodology, addresses issues such as the intended audience, intended application, functional unit (FU), system boundaries, etc.

The intended audiences of this study are researchers who intend to investigate the environmental impacts of construction processes including material delivery systems. The study also targets general contractors, subcontractors, and rebar prefabrication plant managers. The results can be used to advance the understanding of the environmental impacts associated with alternative delivery systems and to inform the construction industry practitioners of the systems with less impact on the environment.

\subsection{Function and FU}

The system function of this LCA project is the production and delivery of raw rebar, as well as fabrication, assembly, transportation, and installation of rebar products on the construction site.

The FU, a measure of the functional output of the systems to be quantified, is the installation of $80,000 \mathrm{~kg}$ of rebar assemblies on the construction site in downtown Seattle, USA, over one week.

\subsection{System boundaries}

The system boundaries of the two rebar delivery systems cover the unit processes that are associated 
with raw material extraction, processing, raw rebar manufacturing at a mill plant, fabrication and assembly of rebars, and installation of the fabricated rebars on the construction site. It will also include the unit processes of the energy sources used within the system boundaries as well as the transportation of materials between the unit processes. Moreover, for a better representation of the practice in reality, the backhauls of transportation loaded with material scraps from the construction site are considered in both systems. Due to the lack of resources and data, however, the supply chains after installation of the rebar products are not included in this cradle-to-gate LCA study. Figures 1 and 2 show the system boundaries of the two delivery systems.

\section{Inventory modeling and analysis}

The "inventory modeling and analysis" is the second phase in the LCA methodology in which the environmental inputs and outputs of the unit processes are tracked and quantified and then, the aggregate environmental flows for the whole system boundaries are calculated.

As stated in the introduction section, the two rebar delivery systems that are studied in this paper include (1) traditional system: on-site fabrication along with large batch delivery, and (2) off-site fabrication (prefabrication) with JIT delivery. The authors investigated the economic and environmental flows associated with application of the two rebar delivery systems at a high-rise condominium construction project in downtown Seattle, USA, from the production of raw rebars to the installation of the rebar cases.

The information about overall rebar processing steps and activities, main equipment use, the energy types and quantities consumed, distances of material transportation, frequency of delivery, and other qualitative information was collected mainly through documentations of the case study project, interviews with the key personnel (project engineers, material procurement managers, general contractor, etc.) at the prefabrication plant, assembly yard and on the construction site, as well as through direct observations.

The documentations of the case study construction project were investigated for tracking the actual data related to the prefab-JIT delivery. The traditional rebar delivery system was then designed based on the modification of the prefab-JIT system used at the case study project. The information needed for the traditional system was built through investigation of literature, interviews with the general contractor, project engineers and the suppliers as well as the authors' calculations.

The study of the application of the two systems in the case study revealed that they vary over certain key operational issues. The main differences between them are summarized in Table 1.

\subsection{Rebar fabrication and assembly process}

A major difference between the two delivery systems has to do with the rebar fabrication and assembly process. As a result of this difference, the equipment type, capacity, and their operating time would be different in the two systems. The equipment productivity and energy consumption per ton of rebar in traditional on-site fabrication system were realized to be lower than those in the prefab-JIT system:

- Traditional delivery system. In traditional system, as shown in Figure 1, rebars are delivered from mill plant to the construction site where they are fabricated, assembled, and installed. Tower cranes, rebar benders/ cutters, and forklifts are the equipment utilized on the construction site to perform the needed processes;

- Prefab-JIT delivery. In prefab-JIT delivery, as shown in Figure 2, rebars are delivered from mill plant to a prefabrication plant where rebars are fabricated and partially assembled. Then, when needed on the construction site, they are transported to the site location where they are installed. In this system, traveling overhead cranes, rebar benders/cutters, and

Table 1. Differences between on-site fabrication and prefab-JIT delivery systems in the case study

\begin{tabular}{|c|c|c|c|}
\hline Item & On-site fabrication system & $\begin{array}{l}\text { Prefab-JIT } \\
\text { system }\end{array}$ & Comment \\
\hline \multicolumn{4}{|l|}{ Equipment operating hours } \\
\hline Crane & 11 & 7.4 & Diesel powered, capacity: $450 \mathrm{hp}$ \\
\hline Rebar bender/cutter & 5.5 & 5 & Electricity powered, capacity: $1200 \mathrm{~W}$ \\
\hline Forklift & 26 & 18 & Diesel powered, capacity: $76 \mathrm{hp}$ \\
\hline Delivery distance (mile) & 27 & 32 & \\
\hline Rebar loss rate $(\%)$ & 10 & 3 & Total installation amount: 80 tons \\
\hline Batch size per truck (ton) & 25 & 21 & \\
\hline Rejection rate in inspection by GC $(\%)$ & 5 & 2 & Delivered fabricated rebar \\
\hline
\end{tabular}




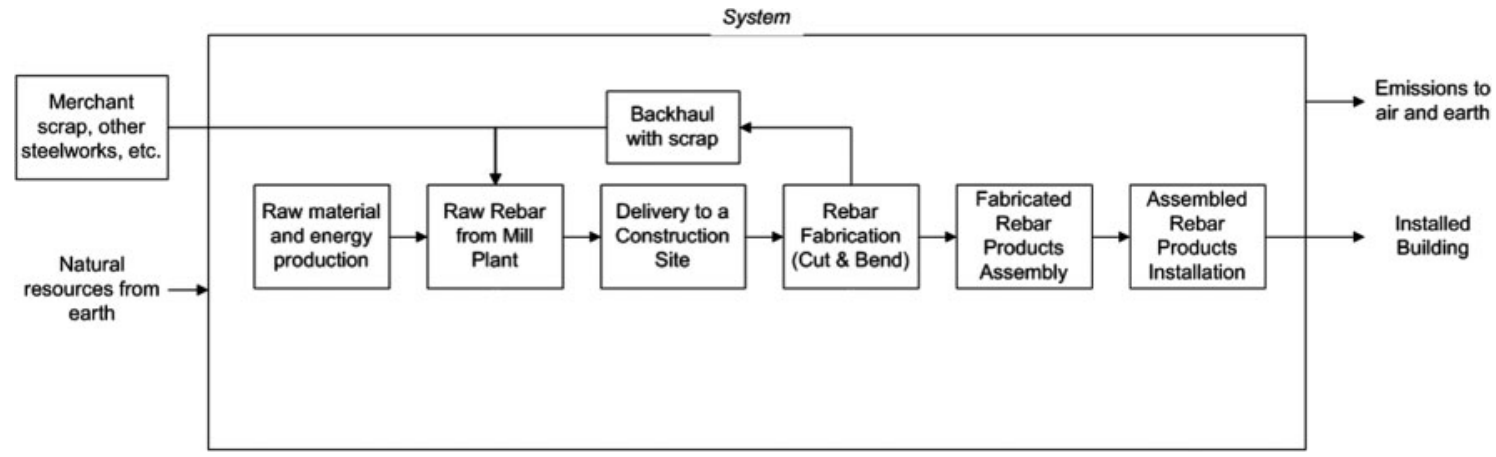

Fig. 1. System boundaries for traditional rebar delivery system (back/scrap twice)

forklifts are used at the prefabrication plant rather than on the construction site. Although the rebar benders/cutters are commonly used in both the on-site and off-site systems, the machine capacities would be different. The offsite plant uses a larger capacity bender/cutter for a lesser operating time compared with the one at the on-site temporary plant.

\subsection{Delivery distance}

The delivery distance influences the delivery time and thus, the fuel consumption and air emissions:

- Traditional delivery system. It was assumed that the rebar supplier, located in Tacoma, USA, delivered raw rebars directly to the construction site in Seattle, USA, which is 27 miles away from the supplier;

- Prefab-JIT delivery. The rebar supplier, located in Tacoma, USA, delivered the raw rebars to the rebar fabrication plant in Tacoma, USA, using heavy-duty trucks. The distance between the two facilities is 5 miles. After fabrication of the rebars at the prefabrication plant, they are delivered to the construction site which is 27 miles away from the plant. The total delivery distance in this system is 32 miles.

\subsection{Rebar loss rate}

Different rebar loss rates for the two systems affect the amount of rebar wastes and the rebar product reproduction. Although the estimated needed rebar quantity for the case study was $80,000 \mathrm{~kg}$, the project engineer ordered additional 3\% of raw rebars in the prefab-JIT system which accounted for an order of $82,400 \mathrm{~kg}$ of rebars. The study revealed that the rebar loss rate in traditional system is $10 \%$ which accounts for a final order of $88,000 \mathrm{~kg}$ of rebars in this system. Different rebar loss rates in the two systems imply different additional equipment working hours that were considered in the modeling.

\subsection{Batch size}

The number and the size of the rebar batches directly influence the frequency of the rebar delivery which, in turn, affect the working time of the applied equipment and subsequently, their energy use. The delivery truck capacity for the two systems, however, was assumed to be the same: 25 tons. The batch sizes of the rebar products in traditional system and in prefab-JIT system were 25 and 21 tons, respectively.

Finally, the inventory databases were used for tracking and quantifying the environmental flows of the unit processes within the system boundaries. These databases include:

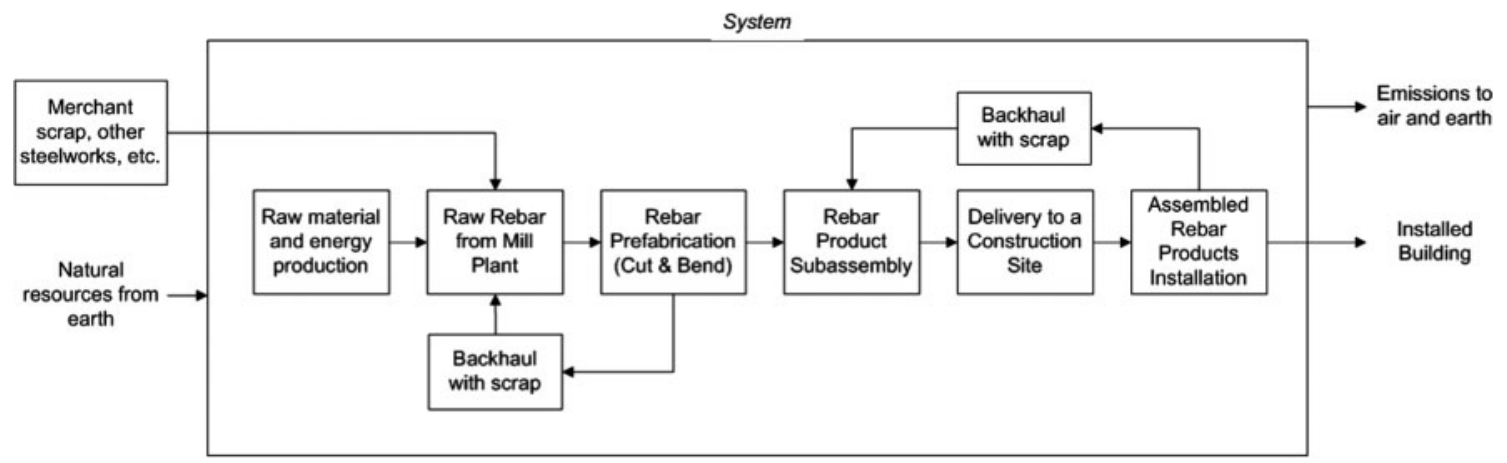

Fig. 2. System boundaries for prefab-JIT rebar delivery system 
- Greenhouse Gases, Regulated Emissions, and Energy Use in Transportation (GREET), provided by Department of Energy (DOE), USA (GREET Database 2011);

- Tool for the Reduction and Assessment of Chemical and other environmental Impacts (TRACI), provided by Environmental Protection Agency (EPA), USA (TRACI 2011);

- NONROAD emissions model, provided by Environmental Protection Agency (EPA), USA (NONROAD Model 2011).

The sources of the data for various unit processes within the system boundaries of the two delivery systems are shown in Table 2.

\subsection{Calculation procedures}

The inventory analysis in this LCA study was conducted using the methodology introduced by Heijungs and Suh (2002). According to the method, the inventory vector as the outcome of the inventory analysis is calculated through the equation:

$$
[\mathrm{g}]=[\mathrm{B}] *[\mathrm{~A}]^{-1} *[\mathrm{f}],
$$

where: $\mathrm{g}$ - inventory vector; $\mathrm{B}$ - intervention matrix; $\mathrm{A}^{-1}$ - inverse matrix of technology matrix, and $\mathrm{f}$ - final demand vector.

To do the inventory analysis, an Excel spreadsheet was created for each delivery system. The inventory data for each system was separated into a technology matrix (A) and an intervention matrix (B). The technology matrix is a square matrix consisting of the economic flows which represent the unit processes within the system boundaries of each delivery system. The technology matrix was composed of all the key unit processes required to generate energy, to produce, fabricate and assemble the raw rebars, and install the rebar assemblies, and to transport the rebar products to the case study construction project's location in Seattle.

The intervention matrix represents the environmental flows associated with the economic flows. Since the environmental impact categories of interest in this LCA study were selected to be acidification, eutrophication, global warming, and smog formation, the environmental flows considered in this research are in fact the major air emissions affecting the impacts categories. These emissions include carbon dioxide $\left(\mathrm{CO}_{2}\right)$, carbon monoxide $(\mathrm{CO})$, methane $\left(\mathrm{CH}_{4}\right)$, nitrogen oxides $\left(\mathrm{NO}_{\mathrm{X}}\right)$, nitrous oxide $\left(\mathrm{N}_{2} \mathrm{O}\right)$, nonmethane volatile organic compounds (NMVOC), and sulfur oxides $\left(\mathrm{SO}_{\mathrm{X}}\right)$.

It should be noted that the data presented in the technology and intervention matrices are not scaled in this method to represent the flows for the unit $(1 \mathrm{~kg})$ of rebar but instead, the data are entered in a way to represent the flows associated with the unit quantity of each unit process. Scaling is then conducted through a

Table 2. Unit processes and inventory data sources

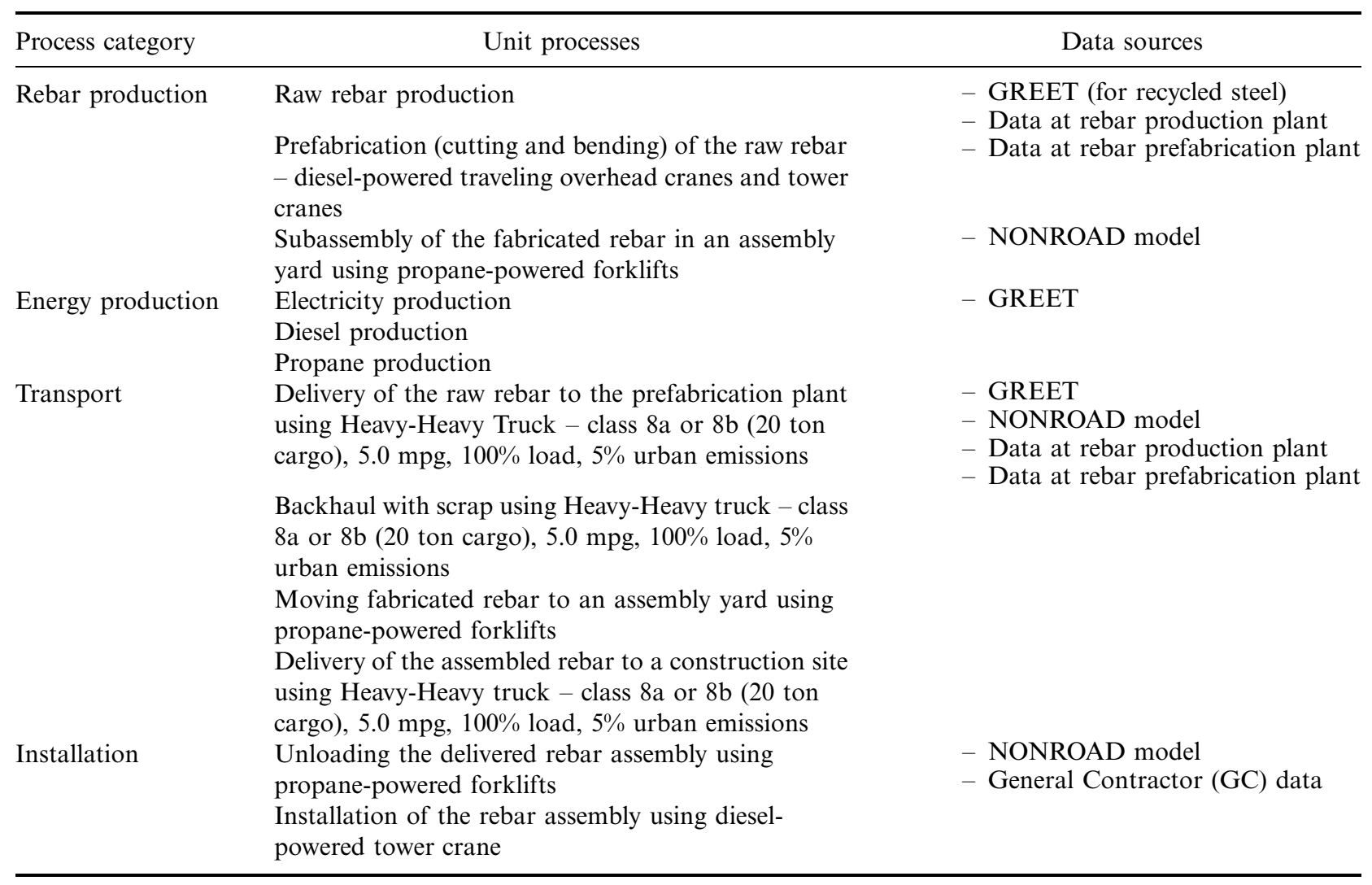


Table 3. Inventory results for the traditional and prefab-JIT delivery systems

\begin{tabular}{lccc}
\hline Emissions & Traditional system $(\mathrm{kg})$ & Prefab-JIT system $(\mathrm{kg})$ & Difference $(\mathrm{kg})$ \\
\hline Carbon dioxide & $5.82 \mathrm{E}+08$ & $5.34 \mathrm{E}+08$ & $4.82 \mathrm{E}+07$ \\
Carbon monoxide & $2.12 \mathrm{E}+06$ & $1.96 \mathrm{E}+06$ & $1.65 \mathrm{E}+05$ \\
Methane & $4.38 \mathrm{E}+05$ & $3.85 \mathrm{E}+05$ & $5.38 \mathrm{E}+04$ \\
Nitrogen oxides & $4.35 \mathrm{E}+06$ & $4.06 \mathrm{E}+06$ & $2.89 \mathrm{E}+05$ \\
Nitrous oxide & $2.76 \mathrm{E}+03$ & $2.42 \mathrm{E}+03$ & $3.39 \mathrm{E}+02$ \\
NMVOC & $2.71 \mathrm{E}+05$ & $2.53 \mathrm{E}+05$ & $1.84 \mathrm{E}+04$ \\
Sulfur oxides & $8.32 \mathrm{E}+05$ & $7.64 \mathrm{E}+05$ & $6.86 \mathrm{E}+04$ \\
\hline
\end{tabular}

part of the equation above. Specifically speaking, it is done by multiplying the inverse of the technology matrix by the final demand vector (f) which represents the set of economic flows that correspond to a reference flow; the only nonzero element in the final demand vector.

Finally, g vector which represents the systemwide aggregated environmental flows and is used for the impact assessment was calculated through the Equation (1).

\subsection{Inventory results}

The results of the inventory modeling of the two rebar delivery systems from the material extraction through rebar generation to the installation of the rebars are shown in Table 3. The values represent aggregated quantity of specified air emissions produced as a result of activities defined by the system boundaries.

\section{Impact assessment}

The impact assessment phase of an LCA study deals with the assessment of contributions of the environmental outputs (which is shown through the inventory results) to the environmental impact categories. Classification and characterization are the essential phases of this phase in the LCA methodology.

\subsection{Classification}

In classification, the focus is on assigning the environmental outputs to the appropriate environmental impact categories including acidification, eutrophication, global warming, and smog formation. The environmental outputs shown in the inventory result (Table 3) are assigned to the impact categories as indicated in Table 4. As the table shows, some air emissions contribute to more than one impact category.

\subsection{Characterization}

In characterization, the quantities of the environmental outputs are multiplied by a characterization factor to achieve the contribution of each environmental output to the impact category of interest. Characterization factors are weighting factors assigned to the environmental outputs to aggregate their contribution to a specific environmental impact category into a score. Characterization factors for this study were provided by TRACI (2011) database.

Table 5 shows global warming potential (GWP), acidification potential (AP), eutrophication potential (EP), and smog potential (SP) for the two delivery systems.

\section{Interpretation}

The interpretation phase in LCA methodology deals with the explanation of the impact assessment results and the analysis of their implications. In the case of this study, contributions of the two delivery systems to the impact categories of study are compared and interpreted. Also in this phase, the limitations of the LCA study are highlighted and the recommendations with respect to overcoming those limitations are made.

\subsection{Global warming}

Global warming is the increase in average temperature on earth surface caused by greenhouse gas emissions (Eyerer et al. 2010). The phenomenon can result in sea level rise, changes in rainfall patterns as well as impacts on living species. GWP is measured in $\mathrm{kg}$ $\mathrm{CO}_{2}$ equivalent.

According to Table 5 and Figure 3, the air emissions resulting from the delivery of rebars in the traditional system cause $8.36 \%$ higher contribution to the global warming, compared with the air emissions in the prefab-JIT delivery system. In both systems, carbon dioxide and methane, respectively, are major drivers of GWP. The contribution to global warming

Table 4. Classification of environmental outputs

\begin{tabular}{|c|c|}
\hline Emissions & Environmental impact category \\
\hline Carbon dioxide & Global warming \\
\hline Carbon monoxide & Smog formation \\
\hline Methane & Global warming, smog formation \\
\hline Nitrogen oxides & $\begin{array}{l}\text { Acidification, Eutrophication, Smog } \\
\text { formation }\end{array}$ \\
\hline Nitrous oxide & Global warming \\
\hline NMVOC & Smog formation \\
\hline Sulfur oxides & Acidification \\
\hline
\end{tabular}


Table 5. Contribution analysis of the delivery methods using TRACI

\begin{tabular}{|c|c|c|c|c|c|}
\hline Delivery system & Emission & GWP $\left(\mathrm{kg} \mathrm{CO}_{2}-\mathrm{e}\right)$ & $\mathrm{AP}(\mathrm{H}+$ moles-e $)$ & EP $(\mathrm{kg} \mathrm{N}-\mathrm{e})$ & SP (kg NOx-e) \\
\hline \multirow[t]{8}{*}{ Traditional system } & Carbon dioxide & $5.82 \mathrm{E}+08$ & 0 & 0 & 0 \\
\hline & Carbon monoxide & 0 & 0 & 0 & $3.53 \mathrm{E}+04$ \\
\hline & Methane & $9.21 \mathrm{E}+06$ & 0 & 0 & $1.61 \mathrm{E}+03$ \\
\hline & Nitrogen oxides & 0 & $1.74 \mathrm{E}+08$ & $1.93 \mathrm{E}+05$ & $5.39 \mathrm{E}+06$ \\
\hline & Nitrous oxide & $8.57 \mathrm{E}+05$ & 0 & 0 & 0 \\
\hline & VOCs & 0 & 0 & 0 & $2.63 E+05$ \\
\hline & Sulfur oxides & 0 & $4.23 \mathrm{E}+07$ & 0 & 0 \\
\hline & Total contribution & $5.92 \mathrm{E}+08$ & $2.16 \mathrm{E}+08$ & $1.93 \mathrm{E}+05$ & $6.10 \mathrm{E}+06$ \\
\hline \multirow[t]{8}{*}{ Prefab-JIT system } & Carbon dioxide & $5.34 \mathrm{E}+08$ & 0 & 0 & 0 \\
\hline & Carbon monoxide & 0 & 0 & 0 & $3.25 \mathrm{E}+04$ \\
\hline & Methane & $8.08 \mathrm{E}+06$ & 0 & 0 & $1.41 \mathrm{E}+03$ \\
\hline & Nitrogen oxides & 0 & $1.62 \mathrm{E}+08$ & $1.80 \mathrm{E}+05$ & $5.03 E+06$ \\
\hline & Nitrous oxide & $7.52 \mathrm{E}+05$ & 0 & 0 & 0 \\
\hline & VOCs & 0 & 0 & 0 & $2.45 \mathrm{E}+05$ \\
\hline & Sulfur oxides & 0 & $3.88 \mathrm{E}+07$ & 0 & 0 \\
\hline & Total contribution & $5.42 \mathrm{E}+08$ & $2.01 \mathrm{E}+08$ & $1.80 \mathrm{E}+05$ & $5.31 \mathrm{E}+06$ \\
\hline Difference & & $4.95 \mathrm{E}+07(8.36 \%)$ & $1.51 \mathrm{E}+07(6.96 \%)$ & $1.28 \mathrm{E}+04(6.65 \%)$ & $3.79 \mathrm{E}+05(6.67 \%)$ \\
\hline
\end{tabular}

in both systems is caused mainly by the use of dieselpowered equipment and raw rebar production.

\subsection{Acidification}

Acidification is the ongoing decrease in the $\mathrm{pH}$ value of rainwater and fog which mainly results from the air pollutants transforming into acids (Eyerer et al. 2010). It is usually measured in hydrogen ion $\left(\mathrm{H}^{+}\right)$mole equivalent or in kilogram sulfur dioxide equivalent.

The LCA results in Table 5 and Figure 3 show that the traditional rebar delivery system compared with the prefab-JIT delivery system makes a $6.96 \%$ larger contribution to acidification. Nitrogen oxides and sulfur oxides are main contributors to this phenomenon in the two systems, respectively. Similar to the global warming category, the contribution to acidification in both systems results mainly from the use of diesel-powered equipment and raw rebar production.

\subsection{Smog}

Smog formation is caused when the pollutants that are discharged from industry and transportation into the atmosphere react with sunlight (Ibanez 2007). The result is damage to the human health, plants, and

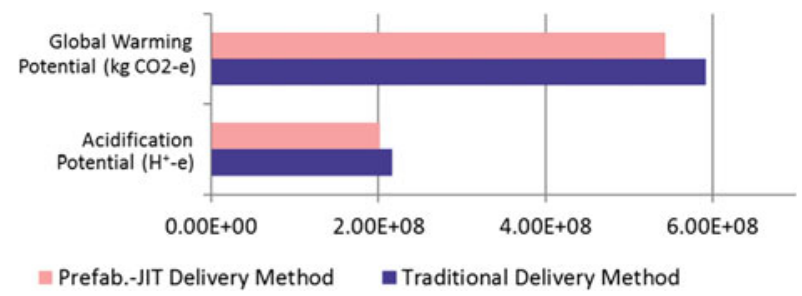

Fig. 3. Total global warming and acidification impact of the delivery systems (needs for re-coloring) animals. Nitrogen oxides are important elements in development of photochemical smog.

As Table 5 and Figure 4 show, the traditional rebar delivery system causes a larger contribution of $6.65 \%$ to smog formation compared with the prefabJIT system. Also, the results show that Nitrogen oxides and volatile organic compounds (VOCs), respectively, are major contributors to smog formation in both systems.

\subsection{Eutrophication}

Eutrophication is defined as the process in which the water bodies become more productive as a result of the increased input of inorganic nutrients (Welch, Jacoby 2004). The outcome of this process is burgeoning growth of algae in the water which blocks sunlight from reaching lower levels of the sea (Eyerer et al. 2010).

Comparison of the LCA results between the two rebar delivery systems shows that $6.65 \%$ more contribution to eutrophication is caused as a result of delivery of rebars in the traditional system compared with their delivery in the prefab-JIT system (Table 5 and Fig. 4). The EP in both systems, however, is caused by the nitrogen oxides that are emitted through the process delivery.

The overall results show that the delivery of rebars in the prefab-JIT system causes less damage to the environment, compared with their delivery in the on-site fabrication system. This happens mainly due to the lower use of fuel- and electricity-powered equipment and the smaller rates of rebar loss in the prefabJIT delivery system. In other words, making a delivery system more efficient and less wasteful, which occurs in the case of prefab-JIT system, also results in less environmental damage. 


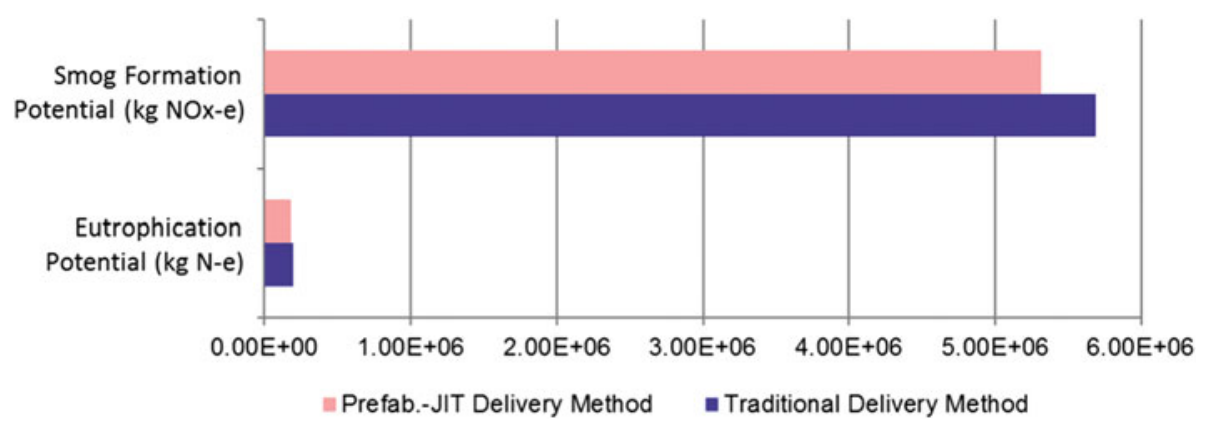

Fig. 4. Total smog and eutrophication impact of the delivery systems

\subsection{Limitations and recommendations}

Data quality is considered as a primary concern with respect to an LCA study. In fact, the lack of reliable representative data, as well as the uncertainties surrounding the subject of LCA studies, affects the validity and reliability of the results. In the case of this study, many players in the rebar supply chain were needed to be reached and interviewed to acquire the needed data. While this was done through the course of this study, investigating more stakeholders in the industry and comparing the data they provide offer a better opportunity for achieving more reliable results. In addition, this research in some cased used the data provided by the publicly available inventory databases to fill the data gaps. Some of these data did not represent the unit processes in this study with respect to the time horizon, geographic location, precision, etc.; as a result of which the overall data and results' quality will be impacted. It is recommended that future research considers collection of representative data from several primary sources in order to improve the data quality issue.

Also due to the lack of resources, this study conducted a cradle-to-gate LCA study instead of a more comprehensive one which includes a full life cycle of the subject of the study. It is recommended that all life cycle phases in both delivery systems are included in a future research.

Another limitation in this research has to do with the research validation. Unfortunately, the authors could not find any other research on the specific subject of this paper whose results could be used for comparison purposes in order to validate its results. Future research on this subject can use the results of this paper to highlight the differences and their sources.

Finally, this research targets a few environmental impact categories for assessing the two systems. It ignores a wide range of other environmental and health impact categories. It also fails to study the social and cost impacts of the two systems. It is recommended that future research expands this study not only within the environmental impact categories but also with respect to other impacts important to the triple-bottom approach. Doing this will provide a better framework to compare the two systems.

\section{Conclusions}

The efficient delivery of reinforced steel rebars is a critical factor in achieving cost and time targets in construction projects. The studies that address the efficiency of delivery systems mostly focus on the process improvements, lead time reductions, and the waste reduction. The environmental impacts are rarely addressed in these studies.

The current study on the environmental impacts of the on-site fabrication and prefab-JIT rebar delivery systems revealed that more efficient, less wasteful delivery systems bring environmental advantages, too. It is especially important to inform contractors that the implementation of wasteful processes not only results in time and cost overruns but also damages the surrounding environment. Also, more research on materials should be encouraged to explore more improvements in their management and delivery processes in order to reduce the wastes through the systems.

\section{Acknowledgments}

This work was supported by the National Research Foundation of Korea's Grant funded by the Korean Government (NRF-2010-013-D00080). The authors would like to thank Professor Joyce Cooper for her valuable comments on the project.

\section{References}

Akel, N. G.; Tommelein, I. D.; Boyers, J. C. 2004. Application of lean supply chain concepts to a vertically-integrated company: a case study, in Proceedings of the 12th Annual Conference of the International Group for Lean Construction, 3-5 August, 2004, Copenhagen, Denmark.

Arbulu, R. J.; Ballard, G. H. 2004. Lean delivery systems in construction, in Proceedings of the 12th Annual Conference of the International Group for Lean Construction, 3-5 August, 2004, Copenhagen, Denmark.

Arbulu, R. J.; Tommelein, I. D.; Walsh, K. D.; Hershauer, J. C. 2003. Value stream analysis of a re-engineered construction supply chain, Building Research and Information 31(2): 161-171.

http://dx.doi.org/10.1080/09613210301993 
Bribián, I. Z.; Capilla, A. V.; Usón, A. A. 2011. Life cycle assessment of building materials: comparative analysis of energy and environmental impacts and evaluation of the eco-efficiency improvement potential, Building and Environment 46(5): 1133-1140.

http://dx.doi.org/10.1016/j.buildenv.2010.12.002

Buchanan, A. H.; Honey, B. G. 1994. Energy and carbon dioxide implications of building construction, Energy and Buildings 20(3): 205-217.

http://dx.doi.org/10.1016/0378-7788(94)90024-8

Eyerer, P.; Weller, M.; Hubner, S.; Agnelli, J. A. 2010. Polymers - opportunities and risks II: sustainability, product design and processing. New York: Springer. $310 \mathrm{p}$.

Gillespie, A. R.; Gustavsson, L.; Eriksson, E.; Langvall, O.; Olsson, M.; Sathre, R.; Stendahl, J. 2007. Integrated carbon analysis of forest management practices and wood substitution, Canadian Journal of Forest Research 37(3): 671-681.

http://dx.doi.org/10.1139/X06-257

GREET Database. 2011. Greenhouse gases, regulated emissions and energy use in transportation model. US Department of Energy's office of Transportation Technologies [online], [cited 12 August 2011]. Available from Internet: http://greet.es.anl.gov/

Gustavsson, L.; Pingoud, K.; Sathre, R. 2006. Carbon dioxide balance of wood substitution: comparing concrete- and wood-framed buildings, Mitigation and Adaptation Strategies for Global Change 11: 667-691. http://dx.doi.org/10.1007/s11027-006-7207-1

Heijungs, R.; Suh, S. 2002. The computational structure of life cycle assessment (Eco-efficiency in industry and science). Dordrecht: Kluwar Academic Publishers. 254 p.

Horvath, A. 2004. Construction materials and the environment, Annual Review of Environment and Resources 29: 181-204.

http://dx.doi.org/10.1146/annurev.energy.29.062403.10 2215

Ibanez, J. G. 2007. Environmental chemistry: fundamentals. New York: Springer. 334 p.

ISO 14040:2006. Environmental management - Life cycle assessment - Principles and framework. Geneva: International Organization for Standardization (ISO). 20 p.

ISO 14044:2006. Environmental management - Life cycle assessment - Requirements and guidelines. Geneva: International Organization for Standardization (ISO). 46 p.
Junnila, S.; Horvath, A. 2003. Life-cycle environmental effects of an office building, Journal of Infrastructure Systems 9(4): 157-166. http://dx.doi.org/10.1061/(ASCE)1076-0342(2003)9:4 (157)

Kim, Y.; Ballard G.; Park, C. 2007. A case of lean implementation: Shift from lean production to lean supply chain management, in Proc. of the 15th Annual Conference of the International Group for Lean Construction, 18-20 July, 2007, East Lansing, Michigan, USA.

Koch, P. 1992. Wood versus nonwood materials in US residential construction: some energy-related global implications, Forest Products Journal 42(5): 31-34.

Meil, J. K. 1994. Environmental measures as substitutional criteria for wood and nonwood building products, in The Globalization of Wood: Supply, Processes, Products and Markets. Forest Products Society Proceedings, 7319, 53-60.

NONROAD Model. 2011. US Environmental Protection Agency [online], [cited 12 August 2011]. Available from Internet: http://www.epa.gov/oms/nonrdmdl.htm.

Petersen, A. K.; Solberg, B. 2005. Environmental and economic impacts of substitution between wood products and alternative materials: a review of micro-level analyses from Norway and Sweden, Forest Policy and Economics 7(3): 249-259. http://dx.doi.org/10.1016/S1389-9341(03)00063-7

Polat, G.; Ballard, G. 2003. Construction supply chains: Turkish supply chain configurations for cut and bent rebar, in Proc. of the 11th Annual Conference on Lean Construction, 22-24 July, 2003, Virginia Tech, Blacksburg, Virginia, USA.

TRACI. 2011. Tool for the Reduction and Assessment of Chemical and Other Environmental Impacts, US Environmental Protection Agency [online], [cited 12 August 2011]. Available from Internet: http://www.epa.gov/ORD/NRMRL/std/sab/traci/index. html.

Welch, E. B.; Jacoby, J. M. 2004. Pollutant effects in freshwater: Applied limnology. 3rd ed. London: Taylor \& Francis. 520 p.

Werner, F.; Richter, K. 2007. Wooden building products in comparative LCA: a literature review, International Journal of Life Cycle Assessment 12(7): 470-479.

Yong-Woo KIM. Associate Professor and P.D.Koon Endowed Professor of Construction Management at the University of Washington, Seattle, WA, USA. He is a member of Lean Construction Institute (LCI) and ASCE. His research interests include lean construction, supply chain management, and activity-based costing.

Rahman AZARI-N. PhD Candidate in Built Environment at the University of Washington, Seattle, Washington, USA. With a background in architectural engineering, his main research interests focus on green building design and delivery, life cycle assessment (LCA) of buildings, building information modeling (BIM), and energy-efficient building design.

June-Seong YI. Associate Professor in the Department of Architectural Engineering at Ewha Womans University, Seoul, Korea. He is a member of Association for the Advancement of Cost Engineering (AACE). His research interests include strategic cost management, supply chain management, and Life-Cycle Assessment (LCA) of buildings.

Jinwoo BAE. Former graduate student of construction engineering and management program at the University of Washington, Seattle, WA, USA. His research interests include lean construction and building information modeling. 